\title{
Correction to: Polyurethane network using 1-naphthylamine embedded epoxy-based polymer: ferric ion selective fluorescent probe
}

\section{Samaresh Ghosh ${ }^{1} \cdot$ Rajkumar Manna ${ }^{1} \cdot$ Swapan Dey ${ }^{2}$}

Published online: 2 September 2020

(c) Springer-Verlag GmbH Germany, part of Springer Nature 2020

\section{Correction to: Polym. Bull. (2019) 76:205-213 \\ https://doi.org/10.1007/s00289-018-2374-2}

This erratum corrects the legends of Fig. 3 (inset) of the published paper. The results presented in the published paper are correct and are not affected by the change in legends of Fig. 3 (inset).

The original article can be found online at https://doi.org/10.1007/s00289-018-2374-2.

Samaresh Ghosh

gsamaresh@yahoo.com

1 Department of Chemistry, Bankura Sammilani College, Kenduadihi, Bankura, West Bengal 722102, India

2 Department of Applied Chemistry, Indian Institute of Technology (Indian School of Mines), Dhanbad, Jharkhand 826004, India 


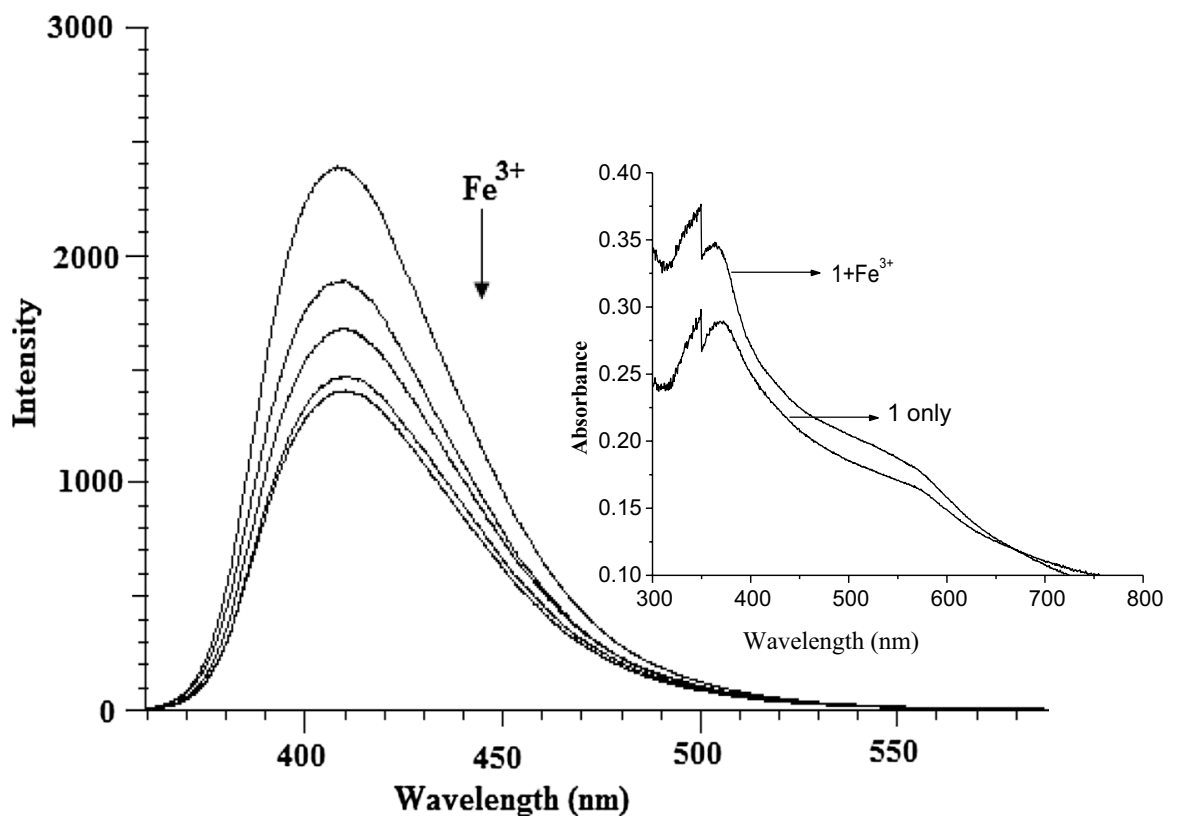

Fig. 3 Fluorescence spectral changes of 1 immersed in HEPES buffered water-EtOH solution of $\mathrm{Fe}^{3+}$ (up to $\left.4.64 \times 10^{-4} \mathrm{M}\right)\left(\lambda_{\text {exc }}=350 \mathrm{~nm}\right)$. Inset: Solid-state UV-Vis spectrum of $\mathbf{1}$ when immersed in $4.64 \times 10^{-4} \mathrm{M} \mathrm{Fe}^{3+}$ solution

Publisher's Note Springer Nature remains neutral with regard to jurisdictional claims in published maps and institutional affiliations. 